\title{
Editorial
}

\section{Hospitais de Ensino: a Trama da Crise}

\section{Teaching Hospitals: the Thread of the Crisis}

\author{
Jadete Barbosa Lampert ${ }^{I}$ \\ Francisco Barbosa Neto \\ Derly Silva Streit ${ }^{I}$ \\ Vardeli Alves de Moraes ${ }^{I}$ \\ Sigisfredo Luis Brenelli
}

No início da década passada, parecia estar encaminhada uma solução para a crônica crise dos Hospitais de Ensino. A publicação e a implementação das Diretrizes Curriculares Nacionais para a área de saúde - em nosso caso, para o curso de Medicina — reduziam a importância do hospital como cenário de prática, em especial o hospital terciário, que constituía, então, a maioria no conjunto da rede de hospitais reconhecidos como "de ensino". Este seria apenas mais um dos múltiplos cenários e não o mais importante, uma vez que deveria se dar "ênfase aos atendimentos primário e secundário" como níveis prioritários para a formação médica.

Em 2003, o novo governo recebeu pela "proa" a crise dos Hospitais de Ensino, com muitos hospitais universitários federais na ponta do iceberg. Um movimento liderado pela Associação Brasileira de Hospitais Universitários e de Ensino (Abrahue) e encampado pela Frente Parlamentar da Saúde, mediante sucessivas audiências públicas, resultou no envolvimento de quatro ministérios e várias entidades relacionadas ao assunto, entre estas a Abem, contempladas na Portaria Interministerial MEC/MS/MCT/MPOG nº 562, de 12 de maio de 2003. Este documento estabeleceu, em seu artigo primeiro, a constituição de uma "Comissão Interinstitucional com o objetivo de avaliar e diagnosticar a atual situação dos Hospitais Universitários e de Ensino no Brasil, visando reorientar e/ou formular a política nacional para o setor" ${ }^{\prime \prime}$. O resultado mais denso e imediato desta ampla comissão foi a Portaria Interministerial MEC/MS no $1.000^{2}$, de 15 de abril de 2004, que estabeleceu as bases para o Programa de Reestruturação dos Hospitais de Ensino (Portaria Interministerial MEC/MS n⿳o $1.006^{3}$, de 27 de maio de 2004, e Portaria MS no 1.7024, de 17 de agosto de 2004).

Decorridos quase dez anos da implementação deste programa, calcado em quatro pilares - Assistência, Ensino, Gestão e Pesquisa -, o balanço atual não é dos mais animadores. O inovador desenho deste programa não foi assimilado em sua totalidade nem mesmo pelos ministérios envolvidos. O Ministério do Planejamento, Orçamento e Gestão, tendo como um de seus maiores desafios no País a implantação de modelos de gestão adequados a organizações complexas - e o Hospital de Ensino é uma das mais complexas -, pouca atenção dedicou ao acompanhamento deste programa. O Ministério da Ciência e Tecnologia, menos ainda. O MEC reduziu seu engajamento desde a criação do Programa de Reestruturação dos Hospitais Universitários Federais (Rehuf), retomando parcialmente após a criação da Empresa Brasileira de Serviços Hospitalares (EBSERH), talvez mais como um "grupo controle" do programa próprio que de uma visão estratégica da importância de ampliar a rede de Hospitais de Ensino para além do próprio quintal. O Ministério da Saúde, que sistematizou e financiou a quase totalidade dos meios necessários à implementação do programa e verdadeiramente liderou a fase inicial do processo, não demorou a tratá-lo como mais um 
de seus "programas", talvez um dos mais trabalhosos e dispendiosos. Em relação a estados e municípios, mesmo tendo os representantes do Conass e Conasems na Comissão Interinstitucional que formulou o programa, com raras e honrosas exceções, o envolvimento dos gestores com o processo oscilou entre a indiferença quase absoluta e um insípido tratamento burocrático.

Em 2003, no início da formulação da "política nacional para o setor", existiam 148 Hospitais de Ensino no País, assim reconhecidos por receberem o Fator de Incentivo ao Desenvolvimento de Ensino e Pesquisa em Saúde (Fideps), e menos de 130 cursos de Medicina. Atualmente, temos mais de 200 cursos de Medicina e pouco mais de 170 hospitais certificados como "de ensino". Se excluirmos deste conjunto os Hospitais Especializados (Inca, Incor, Into, Instituto Dante Pazzanese, Instituto de Infectologia Emílio Ribas, entre outros, mais adequados à pós-graduação que à graduação) e alguns cursos de Medicina que dispõem de mais de um hospital certificado como "de ensino" - Faculdade de Medicina do ABC (4), ESCS/DF (4), FMUSP (3), FCM/Unicamp (3), FM/Unesp (2), FM/UFMG (2), etc. -, é possível que para os demais cursos tenhamos menos de "meio hospital de ensino", em média, para cada curso médico.

Pode-se argumentar que "esta conta não faz sentido", dada a diversidade das dimensões dos hospitais e a grande variação do número de alunos por período, assim como dos projetos pedagógicos em campo. Entretanto, a lentidão no processo de inclusão de hospitais nesta rede tão necessária para qualificar a assistência à saúde, o ensino médico, a gestão hospitalar, a avaliação tecnológica em saúde e a pesquisa clínica tem sido inversamente proporcional à criação de novos cursos de Medicina: se deduzirmos os hospitais que possuíam Fideps quando esta nova política teve início, do total de hospitais hoje certificados como "de ensino", verificaremos que enquanto dois novos hospitais, em média, foram certificados a cada ano, cerca de sete novos cursos de Medicina foram criados por ano, nestes mesmos dez anos. E, para agravar ainda mais a situação, ao mesmo tempo em que se desacelera a certificação de novos hospitais, há uma tendência no atual governo a acelerar a autorização para novos cursos de Medicina.

Este cenário adverso constitui um grande caldo de cultura para a dispersão dos escassos recursos para a educação e a saúde, e desnuda a fragilidade governamental em implementar políticas que exigem ações interministeriais e intersetoriais, podendo agravar ainda mais as precárias condições de formação/capacitação de profissionais de saúde, comprome- tendo a viabilidade do SUS, mesmo a médio prazo. O governo parece se comportar como se estivesse realizando "apostas lotéricas" em "soluções mágicas", como "importação de médicos", autorização de criação de mais cursos de Medicina, "bônus-cenoura", "bolsa assistencial para a saúde suplementar", "prescrições milagrosas" efetuadas pelos denominados "Hospitais de Excelência" (Sírio-Libanês/SP, Israelita Albert Einstein/SP, Samaritano/SP, Moinhos dos Ventos/RS, etc.), podendo também incluir a própria Empresa Brasileira de Serviços Hospitalares (EBSERH) nesta eloquente categoria de mais uma solução mágica.

Resta à sociedade organizada, em sua relação com o governo, estar atenta, criando espaços de análise crítica com manifestações e proposições para a coerência na formulação de políticas de Estado. Políticas que, ao serem implementadas, sejam permanentemente avaliadas e, ajustadas à realidade, se perpetuem em planejamentos de médio e longo prazos, na busca de equidade e justiça.

\section{REFERENCIAS}

1. Brasil. Ministério da Educação. Ministério da Saúde. Ministério de Ciência e Tecnologia. Portaria Interministerial MEC/MS/MCT/MPOG no 562, de 12 de maio de 2003. Constitui a Comissão Interinstitucional com o objetivo de avaliar e diagnosticar a atual situação dos Hospitais Universitários e de Ensino no Brasil, visando reorientar e/ou reformular a política nacional para o setor.

2. Brasil. Ministério da Educação, Ministério da Saúde. Portaria Interministerial MEC/MS nำ1.000, de 15 de abril de 2004. Certifica como Hospital de Ensino as Instituições Hospitalares que servirem de campo para prática de atividades curriculares na área da saúde, sejam Hospitais Gerais e, ou Especializados, de propriedade de Instituição de Ensino Superior, pública ou privada, ou, ainda, formalmente conveniados com Instituições de Ensino Superior. Diário Oficial da União. Brasília, 16 abr. 2004.

3. Brasil. Ministério da Educação. Ministério da Saúde. Portaria Interministerial MEC/MS no 1006 , de 27 de maio de 2004. Cria o Programa de Reestruturação dos Hospitais Universitários de Ensino do Brasil, visando reorientar e, ou formular a política nacional para o setor.

4. Brasil. Ministério da Saúde. Portaria MS no 1702, de 17 de agosto de 2004. Cria o Programa de Reestruturação dos Hospitais de Ensino no âmbito do Sistema Único de Saúde - SUS, e dá outras providências. Diário Oficial da União. Brasília, 18 ago. 2004; Seção 1, p.79. 